\title{
Los enunciados interrogativos al servicio de la cortesía verbal en el siglo XIX: los actos de habla comisivos y exhortativos
}

\section{The Interrogative Speech at the Service of the Verbal Politeness in the 19th Century: Exhortative Speech Acts and Commissive Speech Acts}

\author{
LUCIE Rossowová [145940@mail.muni.cz] \\ Masarykova univerzita, República Checa
}

\begin{abstract}
RESUMEN
El propósito del artículo es estudiar el empleo de los enunciados interrogativos como una estrategia cortés de los actos comisivos y exhortativos en el español peninsular del siglo XIX. Se pretende demostrar mediante los ejemplos ofrecidos que la sintaxis interrogativa no se empleaba en todos los contextos sólo para pedir información sino también para mover cortésmente al interlocutor a una determinada acción. La finalidad del trabajo es profundizar en el conocimiento del funcionamiento de la cortesía lingüística del pasado.
\end{abstract}

\section{Palabras Clave}

Cortesía; enunciado interrogativo; actos de habla exhortativos; actos de habla comisivos; siglo XIX

\begin{abstract}
The purpose of this article is to study the use of interrogative speech as politeness strategies of commissive and exhortative speech acts in European Spanish of the nineteenth century. The examples try to demonstrate that the interrogative syntax was not used only with the purpose of ask for information but also with the purpose of move the hearer to determinate actions politely. The aim of the study is to explore the features of the verbal politeness of the past.
\end{abstract}

\section{KEYWORDS}




\section{Introducción}

El presente artículo pretende demostrar las funciones corteses del enunciado interrogativo y comprobar que éste no se emplea con la única finalidad de preguntar.

La hipótesis del estudio consiste en la suposición de que mediante un enunciado interrogativo es posible formular un acto verbal cortés, que las preguntas no se emplean solamente para pedir información sobre algo sino también para expresar otros actos verbales y transmitir cortesía lingüística. El estudio se centra en el lenguaje decimonónico y pretende ser una aportación a la pragmática histórica.

Para demostrar dicha hipótesis sometemos al análisis un corpus de conversaciones tomadas de fuentes literarias provenientes del siglo XIX. La cortesía del siglo XIX constituye el centro de interés de nuestra tesis doctoral en curso; en ella estudiamos la realización de las estrategias verbales de cortesía del siglo mencionado. A lo largo del análisis ofreceremos ejemplos auténticos de estructuras interrogativas sacados de nuestro corpus que funcionan como una estrategia para expresar un acto de habla cortés. Nos vamos a centrar tan sólo en los actos de habla exhortativos y comisivos, ya que son las dos clases de actos verbales que más se valen de la sintaxis interrogativa para transmitir cortesía verbal.

A la realización de este trabajo nos movieron dos hechos. Por una parte, al observar de una manera general el corpus de actos comisivos y exhortativos nos dimos cuenta de que los dos se realizaban muy a menudo mediante una estructura interrogativa sin que se tratara de preguntas reales. Nos dimos cuenta de que la interrogación constituía una estrategia bastante productiva en cuanto a la realización de dichos actos verbales y en consecuencia decidimos someterla a un estudio más profundo. Por otra parte, no tenemos constancia de la existencia de un trabajo parecido, es decir, de un trabajo que estudie las funciones de los enunciados interrogativos en los actos verbales corteses del idioma español del siglo XIX. Nos parece que al español decimonónico no se le presta todavía la atención suficiente en los estudios cortesiológicos a pesar de que, según nuestra opinión, su estudio puede revelar datos interesantes.

El corpus que es el objeto de nuestro análisis está constituido de enunciados corteses extraídos de novelas y obras de teatro escritas por escritores españoles durante todo el siglo XIX. Los documentos de los que sacamos los ejemplos para el corpus fueron seleccionados al azar no teniendo en cuenta otros aspectos que la nacionalidad del autor (español europeo) y el período de su vida, es decir, el período en el que pudo nacer el documento (siglo XIX). La mayor ventaja de un corpus literario la vemos en la disponibilidad de un contexto lingüístico y situacional más extenso de cada uno de los enunciados, aspecto que facilita la correcta interpretación y la correcta clasificación como una u otra estrategia cortés, y en la riqueza de situaciones comunicativas muy diversas. Los intercambios literarios representan una imitación de un intercambio real, los autores de las obras escribían de manera que sus lectores les entendieran, los consumidores de las obras reconocían muy fácilmente la conducta verbal de los personajes literarios ya que no difería mucho de las interacciones reales. Además, los personajes intentan que los actos que emiten sean oportunos considerando las circunstancias que envuelven la situación de habla. ${ }^{1}$ Por supuesto, somos cons-

1 Fowler (1981: 7) en su trabajo Literature as Social Discourse aduce que: “[...] literature is a kind of discourse, a language activity within social structure like other forms of discourse. It is as amenable to linguistic study as are all other discourses such as conversation, letters, [...], etc." 
cientes de que la naturalidad de la muestra está restringida, hecho que puede limitar parcialmente la validez de las conclusiones. Reconocemos que la escritura, a causa de la estilización literaria y depuración artística, no puede ser un reflejo absolutamente fiel de los usos orales del idioma. Sin embargo, en la perspectiva histórica no hay medio que pueda vencer dicha limitación. En el proceso de la recolección de las fuentes con las que trabajamos nos centramos sobre todo en la nacionalidad y la fecha de la vida de su autor y el género, intentando equilibrar la presencia de autores de prestigio y autores menos conocidos, obras literarias más extensas y piezas más pequeñas para poder reflejar la diversidad del uso cortés del lenguaje.

Considerando la naturaleza histórica y la extensión limitada de nuestra muestra no prometemos ni pretendemos ofrecer una lista definitiva y cerrada de estrategias corteses, sino que se trata más bien de una primera aproximación a la problemática válida para el material que tenemos a nuestra disposición aceptando que los resultados podrían variar, por ejemplo, si el corpus fuera más extenso

\section{Enunciado interrogativo}

En la siguiente cita Escandell Vidal nos brinda su visión acerca de las diferencias entre dos nociones que muchas veces se ven tratadas como si fueran sinónimas, son "interrogación” y "pregunta".

"El significado común a todas las oraciones interrogativas suele buscarse en la equiparación entre los conceptos de 'oración interrogativa' y de 'pregunta': en muchas ocasiones se ha definido una oración interrogativa como aquella que sirve para preguntar. [...]. Si la finalidad de un pregunta es solicitar al destinatario que proporcione una información de la que se carece, resulta claro que ni todas las interrogativas son preguntas, ni todas las secuencias que pretenden que el destinatario dé una determinada información que presentan, necesariamente, una formulación interrogativa" (Escandell Vidal 1999: 3).

Estamos de acuerdo con la opinión de Escandell Vidal. Nosotros tampoco consideramos conveniente crear una equiparación absoluta entre los dos conceptos. Como ya hemos mencionado más arriba, no creemos que todas las interrogaciones sirvan para preguntar, o sea, que puedan considerarse preguntas.

La Nueva gramática básica de la lengua española ofrece la siguiente definición de los enunciados interrogativos:

"Las construcciones interrogativas se caracterizan por introducir una incógnita. En la modalidad interrogativa el emisor no se compromete con la veracidad de lo que expresa la secuencia o dictum, por lo que estos enunciados no son ni verdaderos ni falsos" (RAE, ASALE 2011: 230).

Como vamos a ver en el análisis siguiente, la sintaxis interrogativa no introduce solamente incógnitas o al menos junto a una incógnita a veces tiene otra función ilocutiva; las interrogativas se realizan también con el fin de alcanzar diferentes objetivos perlocutivos. En casos 
concretos no se pretende solamente recibir una respuesta a la incógnita sino que el hablante pretende que el destinatario realice un acto que puede ser, por ejemplo, en los casos de preguntas comisivas aceptar algo o en caso de pregunta exhortativa llevar a cabo una acción que beneficie a uno de los interlocutores (véase más abajo en el análisis).

Y por último presentamos el punto de vista de Gili Gaya "nacen [...] las oraciones interrogativas, caracterizadas en su mayoría por la inflexión final ascendente o circunfleja de su curva de entonación, dando a conocer así que la oración no completa el pensamiento y esperamos que la respuesta lo complete" (Gili Gaya 1994: 46).

Sin embargo, según nuestra opinión muchas construcciones interrogativas no esperan respuesta verbal alguna sino que lo que esperan es una determinada acción. Queremos demostrar que en el siglo XIX (y según nuestra experiencia como hablante del español actual también hoy en día, igual que probablemente en otras etapas históricas de la lengua) representaban, al lado de un simple acto de preguntar y pedir información, un vehículo de expresión de actos verbales corteses diferentes de preguntas que buscan alguna información.

Los destinatarios llegan a la correcta interpretación de este tipo de enunciados al llevar a cabo un proceso inferencial gracias al cual son capaces de deducir lo que el hablante quiere comunicar. Este proceso inferencial Grice lo llama implicatura conversacional, es un principio que regula y describe las interpretaciones de un enunciado. Las implicaturas son inferencias que se pueden calcular teniendo en cuenta las máximas conversacionales y se desarrollan gracias a la relación cooperativa que hay entre los interactantes. Gracias a este mecanismo es posible interpretar de una manera correcta cada enunciado emitido, reconstruir su contenido real, y sobre todo descodificar aquellos enunciados en los que no se expresa literalmente lo que se quiere comunicar. Así el principio de cooperación permite explicar cómo hay que interpretar un mensaje indirecto. Gracias a las implicaturas los destinatarios entienden que lo que se pide no es una información sino la realización de una acción.

En cuanto a las categorías de los enunciados interrogativos hay dos clasificaciones, que se pueden cruzar entre sí. Partimos de la clasificación que presenta Nueva gramática básica de la lengua española (RAE, ASALE 2011:230):

Se trata por un lado de construcciones interrogativas directas o indirectas. Al formar solamente las directas por sí mismas enunciados formalmente interrogativos (p.ej, ¿Quién vino?). Las interrogaciones indirectas se apoyan en una oración subordinada sustantiva, que no lleva puntos interrogativos (p.ej., Dime quién vino.).

El otro grupo de construcciones interrogativas diferencia entre interrogaciones totales o parciales. Con los enunciados interrogativos totales preguntamos sobre todo el contenido de la oración, se puede expresar la incertidumbre entre varias posibilidades (p.ej., ¿Has enviado la carta (o no)?). En las parciales no preguntamos por el predicado de la oración, sino que preguntamos por el sujeto o sus cualidades o por cualquier otro elemento, la incógnita figura en forma de un interrogativo (p.ej., ¿Quién lo hizo?). 


\section{Cortesía verbal}

En este punto consideramos conveniente aclarar brevemente el concepto de cortesía lingüística.

En el presente artículo vamos a tratar el término cortesía como un concepto pragmalingüístico que empezó a recibir tratamiento científico en los años setenta del siglo XX con los trabajos de Lakoff (1970) o Brown y Levinson (1978). En pragmática se entiende por cortesía la capacidad de los hablantes de saber evitar conflictos con los demás, la cortesía facilita las relaciones interpersonales. El modelo de cortesía más desarrollado e influyente fue elaborado por Brown y Levinson (1978). Según estos autores cada miembro de la sociedad reclama para sí una imagen pública; por un lado, todos deseamos que no se nos imponga nada, que tengamos libertad de acción (imagen negativa); y por el otro, deseamos ser apreciados por los demás (imagen positiva). En palabras de los autores:

Central to our model is a highly abstract notion of 'face' which consists of two specific kinds of desires ('face-wants') attributed by interactants to one another: the desire to be unimpeded in one's actions (negative face), and the desire (in some respects) to be approved of (positive face)." (Brown, Levinson 1987: 13) ${ }^{2}$

La cortesía sirve precisamente para esto mismo, para no perjudicar la imagen personal de nuestro interlocutor y para proteger nuestra propia imagen. Por cortesía se pueden explicar, en la mayoría de los casos, las desviaciones de la interacción cooperativa y económica. El nivel de cortesía depende del cálculo de la amenaza para la imagen teniendo en cuenta las categorías de poder, distancia y grado de imposición (Curcó 1998: 130).

Vemos que la cortesía verbal sirve para establecer buenas relaciones interpersonales y para mantener armonía social, pero también se utiliza con objetivos estratégicos, cuando el emisor pretende conseguir cierto beneficio para sí mismo. La cortesía verbal comprende diversos mecanismos lingüísticos, el objetivo de estos mecanismos verbales no es garantizar una transferencia eficaz de informaciones sino que sirven para regular el trato social de los hablantes.

En cuanto a la supuesta universalidad del fenómeno de cortesía que aparece en el modelo de Brown y Levinson, Kerbrat-Orecchioni afirma que "la cortesía es universal: en todas las sociedades humanas se constata la existencia de comportamientos que permiten mantener un mínimo de armonía entre los interactuantes [...] pero, al mismo tiempo, la cortesía no es universal, en la medida en que sus formas y sus condiciones de aplicación varían sensiblemente de una sociedad a otra" (Kerbrat-Orecchioni 2004: 39).

Entonces, la cortesía verbal y el cuidado de la imagen existen en alguna de sus manifestaciones en cada lengua y cada cultura dependiendo del marco socio-cultural de dicha comunidad, se trata de actividades universales, cada sociedad busca el equilibrio entre las imágenes personales de los interlocutores, sin embargo, cada cultura concibe dichos fenómenos de manera diferente. Y consecuentemente, pueden variar también los recursos comunicativos de los que se valgan las

2 "El centro de nuestro modelo lo ocupa una noción muy abstracta que consiste en dos clases específicas de deseos (face wants), que los interactuantes se atribuyen mutuamente: el deseo de que uno no vea impedidos sus actos (imagen negativa) y el deseo de que los actos de uno sean aprobados (hasta cierto punto) (imagen positiva)" (traducción y cita del texto de Carrasco Santana 1999: 4). 
diferentes culturas. Lo mismo ocurre en el nivel temporal de la cortesía verbal, diferentes etapas históricas se caracterizarán por diferentes rasgos en la expresión lingüística de la cortesía.

La cortesía no es una capacidad innata sino que se trata de una conducta adquirida que se va desarrollando mediante el proceso de socialización, de esta manera los seres humanos aprenden desde pequeños a diferenciar entre lo que se valora como un comportamiento socialmente aceptable o inaceptable por una sociedad dada, o sea, como un comportamiento cortés o descortés.

\section{Actos de habla}

Antes de proceder al análisis de los enunciados interrogativos corteses vamos a presentar la teoría de los actos de habla, ya que la taxonomía propuesta por los autores de la teoría de los actos de habla está empleada posteriormente en el estudio.

Los autores de la teoría son los filósofos del lenguaje Austin (1962) y su discípulo Searle $(1969,1976)$. La idea básica de esta teoría es que los enunciados son clases de acciones, que mediante las palabras los hablantes están realizando algo. A través de los actos de habla se alcanza un efecto perlocutivo específico, se intenta mover al destinatario a una determinada acción. Los actos de habla incluyen intenciones de los hablantes. Austin (1998: 138) explica que "puede entenderse que decir algo es hacer algo o que al decir algo hacemos algo e, incluso, que porque decimos algo hacemos algo".

Searle divide los actos de habla en 5 grupos: representativos, exhortativos, comisivos, expresivos y declarativos.

Los actos de habla representativos/asertivos tienen la función de describir estados de cosas del mundo, representar el estado de cosas como real, se basan en la creencia del hablante de que la proposición expresada es verdadera. La función de actos exhortativos consiste en comunicar al oyente que realice o no realice una determinada acción, se basan en la voluntad. Los actos comisivos estriban en comprometer al hablante con el cumplimiento de una acción futura, se apoyan en la intención de realizar un acto. Los actos expresivos tienen como función manifestar el estado psicológico del hablante, representan sus sentimientos y actitud hacia algo o alguien. Y por último, la función de actos declarativos es alterar el estatus, o el estado institucional de algo o alguien, crear situaciones nuevas.

En nuestro análisis nos van a interesar solamente los actos de habla exhortativos y comisivos.

\section{Análisis de enunciados interrogativos corteses}

Vamos a proceder ahora al análisis de los actos de habla exhortativos y comisivos que constituyen los actos que se apoyan con más frecuencia en la sintaxis interrogativa, vamos a poder observar cuáles son las estrategias que se emplean para formular enunciados exhortativos y comisivos corteses. 


\subsection{Los actos de habla exhortativos}

Aquí nos vamos a centrar en los actos de habla exhortativos expresados por el hablante de una manera cortés formulados como enunciados interrogativos.

El objeto ilocutivo de los actos de habla exhortativos es influir en la actuación del destinatario, por este tipo de actos verbales se intenta alcanzar la realización de la acción descrita en el contenido proposicional de la locución pronunciada por el locutor.

Parecen muy productivas las peticiones realizadas mediante una forma interrogativa o además mediante la negación en una forma interrogativa. La pregunta se refiere a la actuación futura del interlocutor. Las interrogaciones mitigan la petición realizada gracias al hecho de que lo que se le pide al otro formalmente parece ser sólo una respuesta afirmativa o negativa. El uso de la negación lo explica el hecho de que la estructura negativa de la proposición facilita al receptor la posibilidad de no aceptar la realización del acto pedido, no colaborar con el emisor.

1. ¿Me permites que te haga vanas preguntas? [Valera 1878: 52]

2. ¿Señora, hará usted el favor de mandar que coloquen mi equipaje en la habitación que me destine usted? [Barrera 1878:14/15]

3. ¿Hay permiso? -Sí, señor. [Zamora y Caballero 1861:13]

4. ¿Me da usted una limosna, que tengo al marido enfermo y desde ayer no he comido? [Pastor 1887:13]

5. Al fin, ¿no me dirás dónde fue? [Breton 1832: 12]

Después de haber observado las muestras de nuestro corpus decimonónico podemos constatar también que en la época que nos ocupa las peticiones se realizaban con frecuencia mediante una perífrasis con el verbo modal poder en una estructura interrogativa y en una forma en la que domina el interlocutor, por ejemplo:

6. Señora, ¿puede usted explicarme lo que pasa? [Licenciado 1869: 31]

7. ¿Podrían ustedes darme razón de una buena doncella y decirme al mismo tiempo si aquí se reciben avisos...? [Luceño 1897:13]

Se trata de una petición cortés formulada a través de una pregunta relativa a la habilidad o capacidad del otro para realizar los deseos del hablante, o sea, se trata de una petición indirecta. El efecto mitigador de la imposición estriba precisamente en la modalidad indirecta de la proposición, ya que aparentemente lo que se le pide al interlocutor es sólo dar una respuesta afirmativa o negativa sobre su capacidad de efectuar lo pedido. De esta manera el oyente no tiene la sensación de que su libertad de acción esté amenazada porque el hablante le ofrece la posibilidad de decidir si va a colaborar con él o no (Orozco 2009: 112). Las preguntas, a diferencia del imperativo, no representan imposiciones directas, puesto que la modalidad interrogativa no se liga directamente con los actos exhortativos, sino que está ligada con las preguntas. De estas construcciones se entiende sin ninguna dificultad que acción se desea ver realizada y quien debería cumplirla. Las preguntas empáticas sobre la capacidad o habilidad del interlocutor se centran en la cortesía negativa. 
Vamos a describir ahora el fondo de los actos verbales indirectos que están muy relacionados con la cortesía lingüística. Los actos de habla indirectos se utilizan con una fuerza ilocutiva diferente de la que parece estar codificada a primera vista por su forma lingüística (Escandell Vidal 1995: 34). Como acabamos de ver en los ejemplos, lo que a primera vista pretende ser simplemente una pregunta es de hecho una petición cortés. Se puede hablar aquí de un enunciado indirecto gracias a la posibilidad de poder interpretarlo de diferentes maneras. A la correcta interpretación del enunciado no llegamos por la simple descodificación composicional de su significado, sino por inferencia y dominio de una convención social. El interlocutor debe hacer inferencias sobre las intenciones comunicativas del que emite la proposición. En realidad, por la voluntad de los hablantes de ser corteses se puede explicar la naturaleza indirecta de muchos actos de habla.

Las peticiones se realizan también como preguntas construidas con el verbo de deseo querer enfocadas hacia el interlocutor (en $2^{\text {a }}$ o $3^{\text {a }}$ persona verbal) y la interrogación de este tipo se refiere a su disponibilidad. Formalmente se presentan como una invitación y en ella solamente se le invita al otro a efectuar la acción solicitada pero no se le manda nada y de esta manera también se le ofrecen más facilidades para negarse a realizar lo solicitado. Como vemos en los ejemplos que siguen, también esta clase de peticiones contiene una especificación del deseo del emisor y la referencia explícita al destinatario de la locución.

8. Pero, ¿me quiere usted dejar en paz? [Pastor 1885: 24]

9. ¿Quiere usted venir á dictarme a gabinete? [Pastor 1889:15]

10. ¿Quiere usted decirme, qué prima le dan para que se case [...]? [Licenciado 1869:14]

\subsection{Los actos de habla comisivos}

El objeto ilocutivo de los actos de habla comisivos es la expresión de la intención del emisor de efectuar una acción que redunda en beneficio del destinatario, la acción suele estar descrita por el contenido proposicional del acto.

En el corpus detectamos interrogaciones comisivas en las que se emplea el verbo poder en la primera persona verbal. En esta estrategia comisiva el hablante explícitamente pide permiso para efectuar un acto en beneficio del interlocutor y el objeto implícito de la interrogación es comprometer al emisor a cumplir el acto prometido. Pidiendo permiso le da a entender al interlocutor que no pretende imponerle su propia voluntad sin que tenga el consentimiento de él para llevar a cabo el acto comisivo.

11. Eso es diferente; pues tú lo quieres, que sea, ¿te puedo servir de algo? ¿Puedo ayudarte en alguna cosa? [Bedoya 1868:63]

12. ¿Puedo hacer algo en obsequio de usted? [Picón 2003:269]

Los verbos querer y preferir representan otro tipo de interrogaciones comisivas, que está relacionado con la llamada condición previa de aceptabilidad. La condición previa de aceptabilidad consiste en que: "el oyente debe preferir que el hablante efectúe el acto prometido a que no lo 
efectúe" (Haverkate 1994:107). La interrogación está orientada al receptor, se refiere a sus deseos. En las ofertas opera con frecuencia también la negación del predicado.

13. ¿Quiere usted abanicarse? -Mil gracias. [Rubí 1849:18]

14. ¿Quieres que vaya yo a la ciudad -cuchicheó la navarra- y le dé aviso al corregidor de lo que nos sucede? [Alarcón 1993:114]

15. ¿Pero no quiere vuecencia tomar un bocado? [Bermejo 1882:35]

16. ¿Prefiere V. que lea unos apuntes que he tomado? [Sanjuán 1923:121]

La condición de aceptabilidad se refleja lingüísticamente también en interrogaciones directas construidas en presente de indicativo que contienen la referencia explícita al emisor. Estas preguntas le invitan al interlocutor que acepte algo del emisor que redunde en su beneficio, es decir, el beneficiario del acto debe ser el interlocutor. Con estas interrogaciones se busca la confirmación del destinatario antes de que se proceda al acto.

17. Al fin, ¿te ayudo? [Vega 1836:32]

18. ¿Le sirvo á usted agua? [Vital 1898:37]

Otra condición previa de los actos comisivos se refiere a la razonabilidad, o sea, a los motivos que existen para realizar el acto, dicha condición se manifiesta lingüísticamente mediante el verbo necesitar en una oración interrogativa enfocado hacia el interlocutor. El predicado no explicita los motivos, sin embargo, implica que si hay necesidad y razones para efectuar el acto comisivo, se pueden explicar. El hablante preguntando por las necesidades de su interlocutor le comunica al mismo tiempo que le importa como persona y que está dispuesto a intentar satisfacerlas si hace falta.

19. Señorita, ¿necesita usted alguna cosa? [Alba 1853:23]

20. - ¿Quieres que te proteja yo? ¿Necesitas algo? - me preguntó con bondad. [Galdós 1876:76]

\section{Conclusión}

En los apartados expuestos más arriba hemos observado el empleo del enunciado interrogativo en el discurso cortés.

Del corpus decimonónico sacamos enunciados exhortativos y comisivos en los que se empleaba la sintaxis interrogativa como una marca de cortesía. A lo largo del análisis comprobamos que no se utilizaban estas interrogaciones a fin de obtener una información de la que se carecía sino para manifestar cortesía verbal y con ella el respeto y salvaguarda de las imágenes de los interlocutores.

La naturaleza cortés de los actos exhortativos construidos con una sintaxis interrogativa estriba en el hecho de que no transmiten sólo un objeto ilocutivo sino dos: un objeto ilocutivo explícito que es la interrogación y uno implícito que es la petición. La interrogación encubre parcialmente el objeto ilocutivo real de la proposición ya que las preguntas sirven primariamente 
para obtener la información solicitada. Hemos visto que un acto exhortativo se puede encubrir por la interrogación, es una manera indirecta y cortés de solicitar algo y análogamente gracias a la posibilidad de interpretar un enunciado exhortativo interrogativo de diversas maneras resulta menor el grado de imposición del acto verbal sobre el destinatario de la locución.

Resumiendo los usos que nos mostró nuestro corpus, una de las posibles alternativas (y a la vez bastante productiva) para expresar actos exhortativos corteses era en el español peninsular decimonónico la interrogación. Para la interrogación exhortativa cortés se aprovechaban predicados conjugados en el presente o futuro de indicativo, el predicado podía ser además negado. Frecuente era también una estructura interrogativa del verbo modal poder y del verbo querer, aportando cada una de las estrategias mencionadas en este párrafo un valor pragmático específico.

En cuanto a los actos comisivos afirmamos que con las interrogaciones se intenta preparar el terreno y mitigar la oferta, ya que aunque se trata de un acto de habla cortés en sí mismo, mediante una oferta o invitación demasiado brusca el destinatario podría pensar que el interlocutor pretende imponerle su propia voluntad y dañar así su imagen negativa. Por el contrario, al emplear la interrogación, que genera ofrecimientos indirectos, se le permite un margen de actuación.

El español peninsular del siglo XIX tendía a mitigar las ofertas por interrogaciones en las que la interrogación podía recaer en un predicado en el presente de indicativo, el verbo modal poder, los verbos volitivos a veces en combinación con su negación o el verbo necesitar, de acuerdo a la función pragmática que se pretendía transmitir para producir efectos corteses.

Como vemos, las interrogaciones exhortativas y comisivas se valían de medios lingüísticos casi similares, la correcta interpretación de tales medios verbales depende del contexto verbal y de la situación de habla. Por esta razón podemos constatar que no convendría establecer correspondencia entre una determinada forma lingüística y un acto de habla específico. Sin embargo, al final hay que subrayar que la cortesía no está inherentemente relacionada con las formas lingüísticas estudiadas; por ejemplo, no todas las preguntas que incluyan el verbo modal poder se pueden catalogar como peticiones corteses, sino que se puede tratar de preguntas reales relativas a la capacidad del interlocutor. El efecto cortés de ciertos medios lingüísticos nace de su interacción con el contenido proposicional y el contexto extralingüístico en el que se encuadran.

\section{Referencias bibliográficas}

\section{Fuentes primarias}

Alarcón, P. A. de. (1993). El sombrero de tres picos. Barcelona: Crítica.

Barrera, P. M. (1878). ;Triste chactas!, Madrid: Imp. de los Señores Rojas.

Bedoya, F. G. de (trad.). (1868). Adriana Lecouvreur. In S. Manero (ed.), Teatro Selecto Antiguo y Moderno, Nacional y Extranjero. Barcelona: Establecimiento Tipográfico-Editorial Salvador Manero.

Bermejo, A. I. (1882). Brillantes americanos. Madrid: Enrique Arregui.

Gutiérrez de Alba, J. M. (1853). Un infierno, o, la casa de huéspedes. Madrid: Imprenta C. González. 
Licenciado Vidriera. (1869). La carta: comedia en tres actos y en prosa. Sevilla: F. Alvarez. Luceño, T. (1897). La niña del estanquero. Madrid.

Pérez Galdós, B. (1876). Napoleón en Chamartín. Madrid: Imprenta de José M.a Pérez.

Pascual de Sanjuán, P. (1923). Flora o la educación de una nina. Barcelona: Hijo de Paluzíe.

Picón, J. O. (2003). La hijastra de amor. Alicante: Biblioteca Virtual Miguel de Cervantes.

Rodríguez Rubí, T. (1849). La ceniza en la frente. Madrid: Imprenta de D.S. Omaña.

Sánchez Pastor, E. (1885). 4 por 100: comedia en un acto y en prosa. Madrid: Florencio Fiscowich.

. (1887). Sereno, Madrid: Imprenta de M.P. Montoya.

. (1889). Los maliciosos. Madrid: R. Velasco.

Vega Carpio, L. de. (1836). El acero de Madrid. Madrid: Imprenta de la Real Compañía.

Vital, A. (1898). La marquesita. Madrid: R. Velasco.

Zamora y Caballero, E. (1861). Una comedia más. Madrid.

\section{Fuentes secundarias}

Austin, J. L. (1998). Cómo hacer cosas con palabras. Barcelona: Paidós Ibérica.

Carrasco Santana, A. (1999). Revisión y evaluación del modelo de cortesía de Brown \& Levinson: Saarbrucken.

Curcó, C. (1998). ¿No me harías un favorcito?: reflexiones en torno a la expresión de la cortesía verbal en el español de México y el español peninsular. In H. Haverkate, G. Mulder y C. F. Maldonado (Eds.), La pragmática lingüística del español. Recientes desarrollos (pp. 129-172). Amsterdam: Editions Rodopi.

Escandell Vidal, M. V. (1995). Cortesía, fórmulas convencionales y estrategias indirectas. In: http://www.uned. es/sel/pdf/ene-jun-95/25-1-Escandell.pdf.

_ (1999). Los enunciados interrogativos. Aspectos semánticos y pragmáticos. In: http://portal.uned.es/ pls/portal/docs/page/uned_main/launiversidad/ubicaciones/04/docente/maria_victoria_escandell_vidal/publicaciones/61-gdle.pdf.

Fowler, R. (1981). Literature as social discourse: the practice of linguistic criticism. Michigan: Indiana University Press.

Gili Gaya, S. (1994). Curso superior de sintaxis española. Barcelona: Biblograf.

Haverkate, H. (1994). La cortesía verbal. Estudio pragmalingüístico, Madrid: Gredos

Kerbrat-Orecchioni, C. (2004). ¿Es universal la cortesía? In D. Bravo y A. Briz Gómez (Eds.), Pragmática sociocultural: estudios sobre el discurso de cortesía en español (pp.39-53). Barcelona: Ariel.

Orozco, L. (2009). El empleo de perífrasis con el verbo poder en la realización de peticiones. In. L. Rodríguez Alfano (Ed.), La (des)cortesía y la imagen social en México. Estudios semiótico-discursivos desde varios enfoques analiticos. (pp. 105-122). Monterrey-Estocolmo: UANL-EDICE.

Real Academia Española, Asociación de Academias de la Lengua Española (2011). Nueva gramática básica de la lengua española. Barcelona: Espasa Libros.

Searle, J. R. (1969). Actos de habla. In Ensayos de filosofía del lenguaje. Madrid: Cátedra. 
